\title{
A qualidade da água de dessedentação animal e a preservação das áreas de preservação permanente
}

\begin{abstract}
No meio rural as interferências nos recursos hídricos estão relacionadas à destruição das áreas de preservação permanentes devido à utilização de agrotóxicos, manejo inadequado do gado e de seus dejetos. As áreas de preservação permanente (APPs) são fundamentais na busca pelo desenvolvimento sustentável, minimizam os impactos da ação pluvial, eólica no solo e garantem a preservação da biodiversidade, estabelecendo o equilíbrio do ambiente. 0 estudo objetivou analisar a qualidade físico-química e microbiológica das águas localizadas em área de preservação permanente (APP), destinadas à dessedentação animal em propriedades rurais produtoras de leite na região do Vale do Taquari-RS, verificando se há relação entre a qualidade da água e a vegetação nativa existente nessas localidades. Por meio de atividades in loco foi realizado, com o auxílio do GPS, o levantamento dos vértices das propriedades rurais delimitando os elementos naturais e demarcando os tipos de usos e coberturas da terra presentes na propriedade. As áreas de preservação permanentes foram delimitadas com base na legislação vigente (BRASIL, 2012). Nesses locais foram coletadas e analisadas amostras de água por meio de parâmetros físico-químicos (amônia, cor, ferro, turbidez, sólidos dissolvidos totais) e microbiológicos (coliformes totais e termotolerantes) com o uso do Kit de Potabilidade Alfakit ${ }^{\circledR}$ e equipamentos de leitura rápida. Os resultados das análises de água foram comparados com o valor máximo permitido de cada parâmetro estabelecido pela Resolução CONAMA no $357 / 2005$ (classe 3). Diagnosticou-se que 33\% das amostras enquadraram-se nos valores máximos permitidos pela legislação vigente quanto a qualidade da água e nessas áreas o percentual da APP coberta por vegetação nativa é inferior a $50 \%$ da área total. Conclui-se que é necessário elaborar e executar projetos que busquem a educação ambiental, para capacitar e conscientizar os produtores rurais.
\end{abstract}

Palavras-chave: Análise da Água; Produtor Rural; Recursos Hídricos.

\section{The quality of animal water and the preservation of permanent preservation areas}

\begin{abstract}
In rural areas interference on water resources are related to the destruction of permanent preservation areas by the use of pesticides, cattle and inadequate management of their waste. The permanent preservation areas (APPs) are essential in the quest for sustainable development, minimize the impacts of storm action, wind on the ground and ensure the preservation of biodiversity, establishing the balance of the environment. The study aimed to analyze the physicalchemical and microbiological quality of water located in permanent preservation area, intended for animal consumption in producing milk farms in the Taquari Vale region-RS, checking for relationship between water quality and existing native vegetation in these locations. Through activities on site was carried out with the aid of GPS, lifting the corners of rural properties delimiting the elements and demarcating the types of uses and land cover present on the property. The Permanent Preservation Areas were defined based on the current legislation (BRAZIL, 2012). These sites were collected and analyzed water samples by means of physico-chemical parameters (ammonia, color, iron, turbidity, total dissolved solids) and microbiological (total and fecal coliforms) using the potability Alfakit ${ }^{\circledR} \mathrm{Kit}$ and fast equipment reading. The results of the water analysis were compared with the maximum value allowed for each parameter set by CONAMA in $n^{\circ} 357 / 2005$ (class 3 ). It was diagnosed that $33 \%$ of the samples conformed to the maximum values allowed by the current legislation regarding water quality and in these areas the percentage of APP covered by native vegetation is less than $50 \%$ of the total area. It is concluded that it is necessary to elaborate and execute projects that seek environmental education, to train and raise awareness among rural producers.
\end{abstract}

Keywords: Water Analysis; Rural Producer; Water Resources.

Topic: Engenharia Ambiental

Reviewed anonymously in the process of blind peer.

Jaqueline de Bortoli

Universidade Federal de Pelotas, Brasil

http://lattes.cnpq.br/1081999900288101

jbortoli@universo.univates.br

Claudete Rempel

Universidade Federal do Rio Grande do Sul, Brasil

http://lattes.cnpq.br/8340497822227462

crempel@univates.br

Mônica Jacheti Maciel

Universidade Federal do Rio Grande do Sul, Brasil

http://lattes.cnpq.br/2575088289818885

monicajm@univates.br

DOI: 10.6008/SPC2179-6858.2017.003.0016
Received: 14/03/2017

Approved: 15/05/2017

\author{
Vitor Emanuel Quevedo Tavares \\ Universidade Federal de Pelotas, Brasil \\ http://lattes.cnpq.br/2905814154843266 \\ veqtavares@yahoo.com.br
}

Referencing this:

BORTOLI, J.; REMPEL, C.; MACIEL, M. J.; TAVARES, V. E. Q.. A qualidade da água de dessedentação animal e a preservação das áreas de preservação permanente. Revista Ibero-Americana de Ciências Ambientais, v.8, n.3, p.170-179, 2017. DOI:

http://doi.org/10.6008/SPC2179-6858.2017.003.0016 


\section{INTRODUÇÃO}

A Constituição Federal, em seu artigo 225, assegura a todos o direito ao meio ambiente ecologicamente equilibrado como condição essencial à sadia qualidade de vida, impondo ao Poder Público e à coletividade o dever de defendê-lo e preservá-lo para presentes e futuras gerações. Para assegurar a efetividade desse direito, a Constituição Federal determina ao Poder Público, entre outras obrigações, que crie espaços territoriais e seus componentes a serem especialmente protegidos em todas as unidades da Federação (BRASIL, 1988).

Neste sentido, as áreas de preservação permanente (APPs) são definidas como áreas nas quais a vegetação deve ser conservada intacta, visando garantir a preservação dos recursos hídricos, da biodiversidade, da estabilidade geológica e do bem-estar dos humanos (ARAÚJO, 2002). Preservar as APPs é de fundamental importância na gestão de bacias hidrográficas, pois contribuem para a estabilidade dos ciclos hidrológicos e biogeoquímicos visando a dar condições de sustentabilidade à agricultura. Intervenções nas APPs para abertura de novas áreas agrícolas comprometerá, no futuro, a reposição de água nos aquíferos, a qualidade de água superficial e subterrânea, perda de solo, ameaças à saúde humana e degradação dos mananciais, além de comprometer a produção de alimentos.

O papel regulador dos ciclos naturais realizado pelas APPs é fundamental para a manutenção do equilíbrio ecológico (TUNDISI et al., 2010). Apesar de essas áreas estarem amparadas por um instrumento legal, verifica-se sua ocupação irregular com agropecuária e uso urbano. No meio rural, as interferências nos recursos hídricos ocorrem por meio da destruição das áreas de preservação permanentes (APPs), pela utilização indiscriminada de agrotóxicos, fertilizantes e pelo manejo inadequado dos dejetos animais e humanos (GONÇALVES, 2003). Em ambiente rural, a mata ciliar nas APPs ao longo de cursos d'água funciona como filtro ambiental, retendo poluentes e sedimentos que chegariam aos cursos d'água, sendo fundamental para o equilíbrio e preservação da biodiversidade, minimizando os impactos da ação pluvial e eólica no solo (SKORUPA, 2003).

A água fornecida aos animais, no meio rural, normalmente é proveniente de fontes naturais como nascentes, arroios, córregos, banhados e açudes, pela praticidade e baixo custo (AMARAL et al., 2003; DIAS, 2006). A qualidade da água é importante pois reflete no desempenho produtivo e no bem-estar animal (TAVARES et al., 2012). Se a água for de baixa qualidade pode transmitir numerosos agentes infecciosos e ocasionar gastroenterites, hepatites, infecções respiratórias e generalizadas (CERQUEIRA et al., 2006).

O objetivo do presente estudo foi analisar a qualidade físico-química e microbiológica das fontes de água localizadas em área de preservação permanente, destinadas à dessedentação animal em propriedades rurais produtoras de leite na região do Vale do Taquari/RS, e verificar se existe relação entre a qualidade da água e o percentual de vegetação nativa presente nas áreas de preservação permanente nessas localidades. 


\section{MATERIAIS E MÉTODOS}

\section{Área de Estudo}

A região do Vale do Taquari/RS pertence à bacia hidrográfica do sistema Taquari-Antas que se situa na região nordeste do estado do Rio Grande do Sul, abrangendo a área de $26.428 \mathrm{~km}^{2}$, $9 \%$ do território estadual, e 119 municípios, inseridos total ou parcialmente. Limita-se ao norte com a bacia do rio Pelotas, a oeste e ao sul com a bacia do rio Jacuí e a leste com as bacias dos rios Caí e Sinos (SEMA, 2016).

O Vale do Taquari, formado por 36 municípios, conforme ilustrado na figura 1, está localizado na região central do Rio Grande do Sul. Apresenta uma área total de $4.826,7 \mathrm{~km}^{2}$, onde residem 348.435 habitantes (IBGE, 2015). Essa população é formada por diversas etnias, origem alemã, italiana e açoriana. Além disso, destacam-se 43 mil produtores rurais, envolvidos em pequenas e médias propriedades no meio rural, essas famílias dedicam-se à agricultura e pecuária elevando significativamente região do Vale do Taquari em segunda colocação em produtividade rural. Além do setor agropecuário, outros municípios estão desenvolvidos na indústria e comércio.

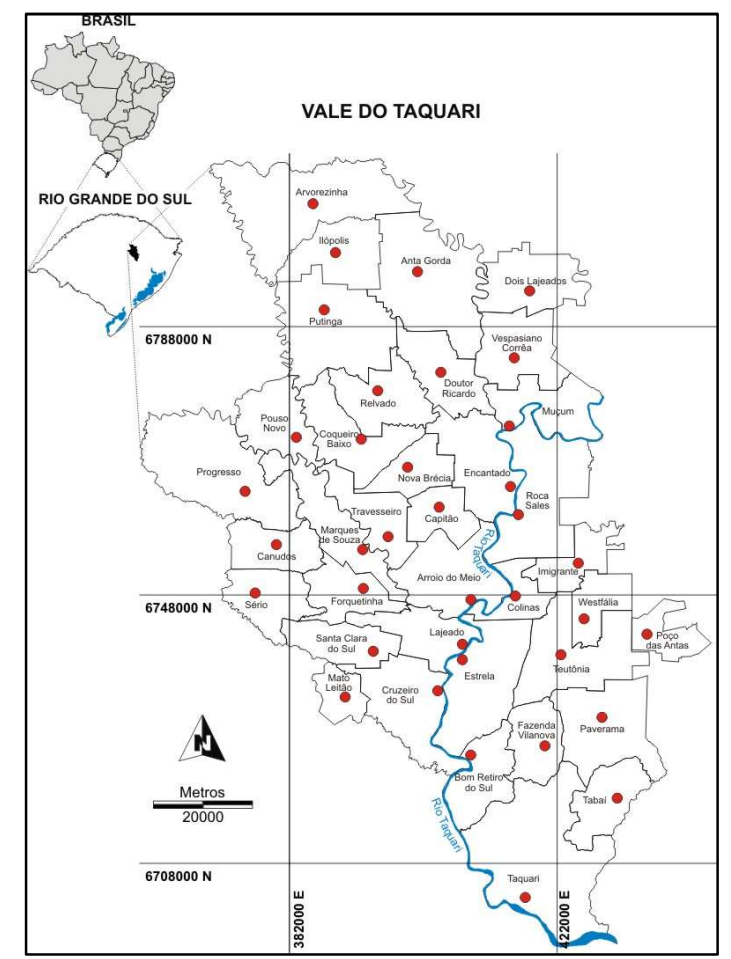

Figura 1 - Mapa de Localização da região do Vale do Taquari/RS. Fonte: Eckhardt et al. (2013).

\section{População e amostra}

Este estudo foi desenvolvido em 15 propriedades rurais com produção de leite em 14 municípios do Vale do Taquari/RS. Nesses locais, evidenciou-se presença de APPs de curso d'água: arroios, banhados e córregos, ou seja, faixas marginais de qualquer curso d'água natural perene e intermitente (BRASIL, 2012), que são utilizados como principal fonte de dessedentação animal.

Para estabelecer proporcionalmente o número de amostras das propriedades rurais com produção de leite utilizaram-se os dados do Censo Agropecuário (IBGE, 2006), de modo que a amostra tivesse 95\% de 
confiança, sendo as Secretarias de Agricultura e Empresa de Assistência Técnica e Rural (EMATER) responsáveis por indicar quais as propriedades rurais participantes do estudo.

\section{Coleta e análise dos dados}

O estudo foi conduzido no período de janeiro a junho de 2015; posteriormente, iniciaram-se as atividades in loco nos estabelecimentos rurais selecionados. Durante as atividades de campo foi possível conhecer e observar aspectos relevantes sobre a propriedade rural (localização da fonte, onde está situada, riscos de contaminação, entre outros).

Nas atividades de campo foi realizado o levantamento dos vértices das propriedades rurais com auxílio de GPS, delimitando os elementos naturais e demarcando os tipos de usos e coberturas da terra presentes na propriedade, as áreas de preservação permanentes (APPs) foram delimitadas com base na legislação vigente (BRASIL, 2012). Também foi realizada a coleta de uma única amostra de água da principal fonte de água destinada à dessedentação animal, para tanto, seguindo a metodologia proposta pelo Manual Prático de Análise de Água (FUNASA, 2004) para os parâmetros físico-químicos e microbiológicos. As amostras foram armazenadas em frascos de vidros, identificados e acondicionados em caixas térmicas até o local das análises (Laboratório de Química e Microbiologia do Centro Universitário Univates).

Quanto à análise microbiológica coliformes totais (Enterobacter cloacae) e coliformes termotolerantes (E. coli), foram realizadas a partir de cartelas prontas com o meio de cultura em forma de gel desidratado que é capaz de detectar e quantificar a presença de coliformes totais e termotolerantes (Meio cromogênio em dip slide em papel - Colipaper - concentração mínima detectável 80 UFC/100 mL Meio rastreado à cepa bacteriana Escherichia coli para coliformes termotolerantes e Enterobacter cloacae para coliformes totais).

A leitura do número de coliformes nas cartelas foi realizada com o auxílio do contador de colônias. Os pontos vermelhos, azuis e violeta, na cartela, representavam coliformes totais e pontos azuis e violetas, na cartela, representavam coliformes termotolerantes. Para expressar o valor de UFC (Unidade Formadora de Colônia) multiplicou-se o fator de correlação (80) pelo valor encontrado em cada cartela.

Tabela 1: Parâmetros físico-químicos e microbiológicos analisados com respectivas marcas e metodologias utilizadas.

\begin{tabular}{|c|c|c|}
\hline Parâmetros (Unidade) & Equipamento & Marca/Modelo \\
\hline $\begin{array}{l}\text { Coliformes Totais e } \\
\text { Termotolerantes (UFC/ } 100 \mathrm{~mL} \text { ) }\end{array}$ & - & Alfakit \\
\hline Amônia (mg L-1) & - & Alfakit \\
\hline Cor (mg Pt-Co L-1) & Colorímetro & Digimed/ DM-COR \\
\hline $\mathrm{pH}$ & pHmetro & Digimed/DM-20 \\
\hline Ferro $\left(\mathrm{mg} \mathrm{L}^{-1}\right)$ & - & Alfakit \\
\hline Oxigênio Dissolvido $\left(\mathrm{mg} \mathrm{L}^{-1}\right)$ & Oxímetro & Digimed/DM-4P \\
\hline Turbidez (NTU) & Turbidímetro & Digimed/ DM-TU \\
\hline Oxigênio Dissolvido (mg L-1) & Oxímetro & Digimed/DM-4P \\
\hline $\begin{array}{l}\text { Sólidos Dissolvidos Totais (mg L- } \\
\text { 1) }\end{array}$ & $\begin{array}{c}\text { Forno-Mufla/ Balança-analítica/ } \\
\text { Cadinho / Dessecador/ Temporizador }\end{array}$ & $\begin{array}{c}\text { Splabor/ Balança Bel engineering/ Cadinho de } \\
\text { Gooch/ Dessecador Vidrolabor/ Temporizador Coel }\end{array}$ \\
\hline
\end{tabular}

Para cada amostra coletada analisou-se: coliformes totais e termotolerantes, turbidez, cor, $\mathrm{pH}$, amônia, ferro e sólidos dissolvidos totais (tabela 1). Cada parâmetro foi analisado em triplicatas, por equipamento específico ou pelo Kit de Potabilidade Alfakit ${ }^{\circledR}$ (código 2693), com metodologia própria. O kit é 
indicado para avaliar a qualidade da água e o monitoramento da água em poços, água tratada por famílias, escolas ou empresas, é prático, seguro quanto ao manuseio dos reagentes e de fácil interpretação. Estudos envolvendo análise de parâmetros físico-químicos e microbiológicos se valeram do mesmo método para diagnóstico da água (FERREIRA et al., 2012; ZAN et al., 2012). Para a análise de sólidos dissolvidos totais seguiu a metodologia Association of Official Analytical Chemistry (AOAC, 1995).

Os resultados obtidos foram organizados em planilhas, sendo que os valores para as análises de água foram comparados com a Resolução do CONAMA n 357 de 2005 (classe 3). Os mapas foram analisados individualmente e por meio do teste de Correlação $p$ de Spearman foram comparados os valores de coliformes termotolerantes e percentual de mata nativa existente, podendo assim, verificar a relação de um fator com o outro.

\section{RESULTADOS E DISCUSSÃO}

Os parâmetros físico-químicos e microbiológicos são determinantes nas características da água, garantindo que a mesma possa ser consumida sem qualquer risco, de forma segura e confiável (SPERLING, 2005; RICHTER NETO, 2013). É necessário que padrões de potabilidade estejam embasados legalmente. No Brasil, o padrão de qualidade para águas está estabelecido na Resolução CONAMA n³57 de 2005, que "dispõe sobre a classificação e diretrizes ambientais para o enquadramento dos corpos de água superficiais" (CONAMA, 2005).

O artigo $3^{\circ}$ da Resolução do CONAMA n³57 de 2005 (CONAMA, 2005) classifica os corpos de água em: águas doces, salobras e salinas do Território Nacional, segundo a qualidade requerida para os seus usos preponderantes, em treze classes de qualidade. As águas de melhor qualidade podem ser aproveitadas em uso menos exigente, desde que este não prejudique a qualidade da água. 0 Artigo $4^{\circ}$ da Resolução do CONAMA n³57 de 2005 (CONAMA, 2005) classifica as águas superficiais doces em classe especial, classe 1, classe 2 , classe 3 e classe 4 .

Portanto, para o estudo desenvolvido, utilizou-se como referência para as águas doces superficiais destinadas à dessedentação animal, classe 3, uma vez que a legislação descreve a finalidade do seu uso, de acordo com a classe estabelecida. Os parâmetros físico-químicos e microbiológicos exigidos pela Resolução do CONAMA n 357 de 2005, são apresentadas na Figura 2 com o valor máximo permitido estabelecido para cada parâmetro analisado descritos nos artigos 14, 15 e 16 da referida legislação conforme se nota na tabela 2.

Tabela 2: Parâmetros físico-químicos de qualidade da água e valor de referência estabelecido, classe 3, conforme a Resolução do CONAMA n³57 de 2005.

\begin{tabular}{|l|c|}
\hline \multicolumn{1}{|c|}{ Parâmetros } & Valor máximo permitido \\
\hline Ferro $\left(\mathrm{mg} \mathrm{L}^{-1}\right)$ & Não definido \\
\hline $\mathrm{pH}$ & 6,0 a 9,0 \\
\hline Turbidez (NTU) & Até 100 \\
\hline Cor $\left(\mathrm{mg} \mathrm{L}^{-1} \mathrm{Pt}-\mathrm{Co}\right)$ & 75 \\
\hline Sólidos dissolvidos totais $\left(\mathrm{mg} \mathrm{L}^{-1}\right)$ & 500 \\
\hline Coliformes totais (UFC/100 $\mathrm{mL})$ & Não definido \\
\hline Coliformes termotolerantes $(\mathrm{UFC} / 100 \mathrm{~mL})$ & 1000 \\
\hline
\end{tabular}

Fonte: CONAMA (2005). 
A água está relacionada com a produção de leite, uma vaca em lactação é capaz de ingerir de 4 a $6 \mathrm{~L}$ de água por quilo de matéria seca da ração, isto é, de 40-60L de água por dia. Experimentos demonstraram que as vacas que possuem acesso a água todo o dia, produzem de 4 a $5 \%$ de leite a mais do que aquelas com acesso somente duas vezes, e 6 a 11\% do que aquelas com acesso à água uma só vez ao dia. Em dias quentes as vacas de alta produção de leite, ingerem, no mínimo, 90L de água por dia (PEREIRA et al., 2009). As amostras de água coletadas nas APPs estão expressas na figura 2. Os resultados das análises das amostras de água coletadas e analisadas nas 15 propriedades rurais durante o primeiro semestre de 2015 estão apresentados na tabela 3.
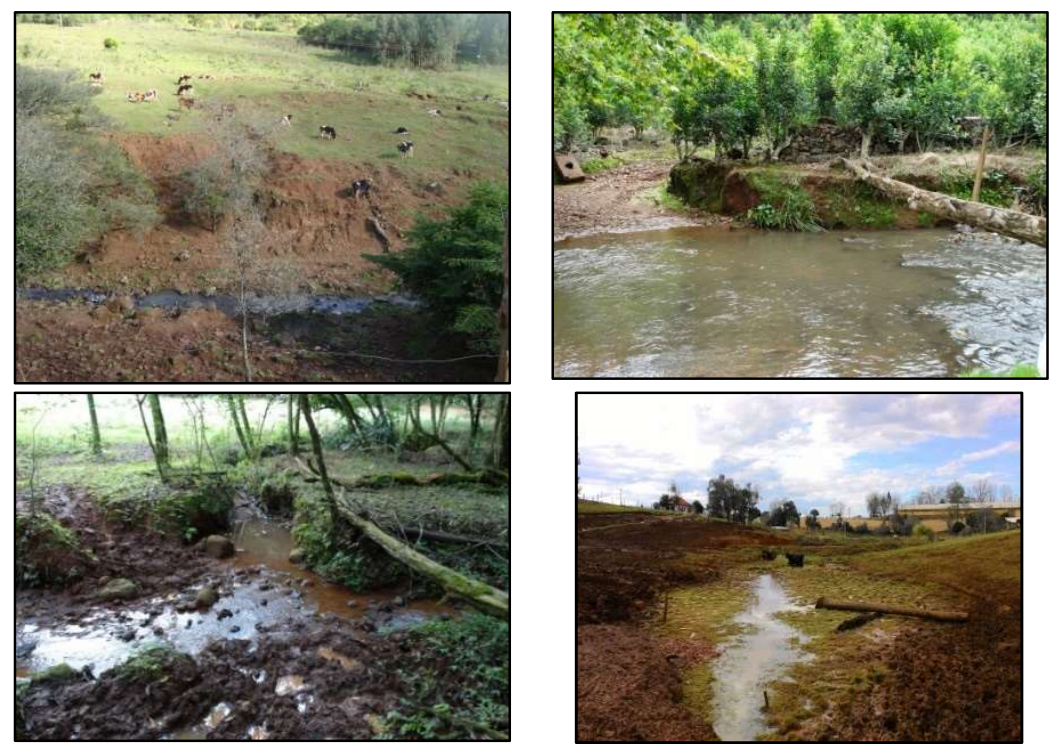

Figura 2: Fontes de abastecimento localizadas em área de preservação permanente utilizadas para a dessedentação animal nas propriedades rurais produtoras de leite na região do Vale do Taquari/RS.

Tabela 3: Parâmetros e resultados físico-químicos e microbiológicos da água de dessedentação animal.

\begin{tabular}{|c|c|c|c|c|c|c|c|c|}
\hline Amostras & $\begin{array}{c}\text { Colif. Totais } \\
\text { (UFC/100mL) }\end{array}$ & Colif. Termot. (UFC/100mL) & $\begin{array}{c}\text { Amônia } \\
\left(\mathbf{m g ~ L}^{-1}\right)\end{array}$ & $\mathbf{p H}$ & $\begin{array}{c}\text { Turbidez } \\
\text { (NTU) }\end{array}$ & $\begin{array}{c}\text { Cor } \\
\text { (mg Pt-Co L-1) }\end{array}$ & $\begin{array}{c}\text { Ferro } \\
\text { (mg L-1) }\end{array}$ & $\begin{array}{c}\text { Sól. Dis. } \\
\text { Tot. }\end{array}$ \\
\hline $\mathbf{1}$ & 2984 & 960 & 0,1 & 8,47 & 10,45 & 28,23 & 0 & 223,33 \\
\hline $\mathbf{2}$ & 2720 & 80 & 0,33 & 7,65 & 5,31 & 29,93 & 0 & 280,00 \\
\hline $\mathbf{3}$ & 3360 & 2080 & 0,2 & 8,93 & 15,56 & 38,20 & 0 & 126,67 \\
\hline $\mathbf{4}$ & 12904 & 8800 & 0,25 & 8,93 & 202,33 & 0,00 & 1 & 203,33 \\
\hline $\mathbf{5}$ & 10664 & 3556 & 0,2 & 9,04 & 13,63 & 34,57 & 0 & 160,00 \\
\hline $\mathbf{6}$ & 1520 & 194 & 0,1 & 8,89 & 3,99 & 24,67 & 0 & 163,33 \\
\hline $\mathbf{7}$ & 2664 & 2376 & 0,1 & 7,69 & 6,85 & 33,63 & 0 & 410,00 \\
\hline $\mathbf{8}$ & 1016 & 480 & 0,1 & 7,86 & 2,92 & 21,03 & 0 & 70,00 \\
\hline $\mathbf{9}$ & 6000 & 4456 & 0,1 & 8,67 & 11,58 & 28,67 & 0 & 90,00 \\
\hline $\mathbf{1 0}$ & 7944 & 3280 & 0,33 & 8,10 & 23,23 & 77,87 & 0 & 43,33 \\
\hline $\mathbf{1 1}$ & 56 & 3728 & 0,1 & 7,03 & 18,55 & 53,67 & 0 & 273,33 \\
\hline $\mathbf{1 2}$ & 11576 & 9600 & 0,10 & 7,16 & 121 & 0,00 & 0 & 346,67 \\
\hline $\mathbf{1 3}$ & 1576 & 824 & 0,10 & 7,19 & 48,67 & 0,00 & 1 & 170,00 \\
\hline $\mathbf{1 4}$ & 10616 & 8720 & 0,07 & 7,80 & 324,33 & 0,00 & 0,25 & 200,00 \\
\hline $\mathbf{1 5}$ & 2536 & 1360 & 0,1 & 7,06 & 28,33 & 53,03 & 0 & 193,33 \\
\hline
\end{tabular}

Os parâmetros físico-químicos: amônia, ferro e sólidos dissolvidos totais apresentaram os valores de acordo com o permitido pela legislação consultada. O potencial hidrogeniônico $(\mathrm{pH})$ expressa a concentração do íon hidrogênio e a intensidade da condição ácida ou básica de uma solução (FUNASA, 2004; SPERLING, 2005). Um pH baixo representa potencial corrosivo e em concentrações altas há possibilidade de incrustações nas tubulações de abastecimento (LENZI et al., 2009). Por isso, o pH é um parâmetro importante de ser 
analisado e controlado em um corpo hídrico, uma vez que ele está relacionado aos processos biológicos no meio aquático (SPERLING, 2005). No estudo, observou-se que a Amostra 5 encontrou-se acima do permitido pela legislação vigente, que permite valores de 6 a 9.

A turbidez é um parâmetro que identifica as partículas sólidas em suspensão (presença de plâncton, algas, detritos orgânicos, zinco e ferro, etc.) provenientes de um processo natural de erosão ou de despejos domésticos e industriais. Os períodos de chuva favorecem o carreamento de solo para lagos e rios aumentando a turbidez (LENZI et al., 2009). Os valores encontrados para o parâmetro turbidez nas amostras 4 e 14, que apresentaram valores elevados para tal parâmetro pode estar relacionado a quantidade de matéria orgânica ou excesso de chuva nos locais, na qual houve concentração das partículas em estado coloidal, em suspensão, causadora da turbidez (MOLINA, 2006; FERNANDES, 2011).

Segundo Rocha et al. (2006) ao avaliar a qualidade da água e percepção higiênico-sanitária na área rural de Lavras, Minas Gerais, verificou que 70\% das amostras obtiveram valores acima do permitido para o parâmetro turbidez, associadas a outros parâmetros analisados, cor e coliformes totais, evidenciando que a água destinada à dessedentação de animais e demais usos nessas propriedades rurais oferece risco à saúde da população bem como afeta o bem-estar animal.

Quanto aos resultados obtidos para o parâmetro cor, Libânio (2010) afirma que os compostos orgânicos que conferem cor às águas naturais são provenientes da decomposição de matéria orgânica vegetal, resultado do metabolismo de microrganismos presentes no solo e das atividades antrópicas. Constatou-se que nas amostras analisadas, a Amostra 10 encontrou-se acima do valor estabelecido pela legislação vigente.

Ao caracterizar a qualidade de águas superficiais em Rondônia, Zuffo et al. (2013) verificaram que o parâmetro cor, esteve acima de $75 \mathrm{mg} \mathrm{Pt} / \mathrm{L}^{-1}$, estando os valores máximos de coloração nesses locais entre 110 e $175 \mathrm{mg} \mathrm{Pt} / \mathrm{L}^{-1}$. Esses valores revelaram maior grau de poluição dessas águas, ao comparar com as amostras de água da região do Vale do Taquari, os valores para este parâmetro apresentaram-se pouco acima

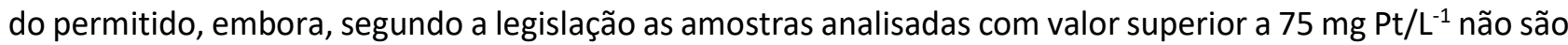
consideradas próprias para a dessedentação animal.

Os coliformes termotolerantes representados, principalmente, pela espécie Escherichia coli, têm sido utilizados no monitoramento da qualidade de águas, sendo considerados os mais específicos indicadores de qualidade de águas destinadas a potabilidade e balneabilidade (NOGUEIRA, et al., 2003; SANTANA et al., 2003). Deste modo, as alterações da qualidade da água são resultantes do impacto das atividades antrópicas sobre a natureza, manejo inadequado do gado, solo e outras variáveis. O homem não tem consciência de que os recursos naturais são finitos e que os recursos hídricos estão sendo utilizados como depósito de rejeito comprometendo as características do meio aquático (BRANCO, 2010).

Os testes microbiológicos detectaram valores acima do permitido, segundo a Resolução CONAMA n³57 de 2005 (classe 3), para coliformes termotolerantes em 10 amostras. A qualidade da água destinada à dessedentação animal é importante no que se refere à saúde e desempenho animal, os produtores rurais 
devem estar cientes de que a água de má qualidade leva a perdas na produção do leite, além de aumentar o risco de disseminação de doenças ao ser mantido contato com esta água.

$\mathrm{Na}$ região do Vale do Taquari, foram elevados os valores encontrados para coliformes termotolerantes, isso se justifica, em algumas amostras, pela ausência de proteção dos poços, estando o gado em contato direto com a fonte de água que é fornecida a eles pelos tanques/bebedouros. Nos açudes, banhados e arroios, isso pode estar associado à entrada contínua do gado nesses locais, acentuando o pisoteio e aumento de coliformes, já que o gado tem acesso livre às áreas de potreiros ou pastagens. Impedir que os animais transitassem próximo das fontes da água de dessedentação, disporem em vários lugares os bebedouros e em altura adequada, contribuindo na diminuição dos riscos de contaminação por fezes e impurezas que o gado pode levar em seu casco.

Diversos são os modelos propostos para o monitoramento da água e medidas para redução de coliformes termotolerantes em cursos d'água. A dificuldade está em determinar quais são os pontos específicos de contaminação. É importante haver conscientização e melhorar a prática de manejo, reduzindo o acesso dos animais nos cursos d'água, diminuindo a contaminação por E.coli, uma vez que o pisoteio do gado favorece o assoreamento e compactação das margens do curso d'água (LAWARE et al., 2006).

A gestão adequada dos recursos hídricos está se tornando uma necessidade em função do aumento das populações e da escassez de água. Para um manejo adequado, a primeira necessidade é de informação. Para isto, os procedimentos mais adequados são o monitoramento ambiental integrados e sequencial dos recursos, para reconhecer seu estado e as causas que atuam na sua qualidade.

A água é um importantíssimo suporte ao desenvolvimento de um dos maiores potenciais de biodiversidade da Terra e de produção da biomassa. Assim, o nosso grande potencial de água deve ser visto como um capital ecológico de inestimável importância e fator competitivo fundamental ao desenvolvimento socioeconômico sustentado.

Tabela 4: Total de APPs nas amostras estudadas.

\begin{tabular}{|c|c|c|c|}
\hline Amostra & Hectares (ha) & Área total da APP na propriedade (ha) & Área com vegetação native na APP (\%) \\
\hline 1 & 18,3 & 0,7 & 55,8 \\
\hline 2 & 18,06 & 8 & 56,03 \\
\hline 3 & 27,4 & 1,17 & 38,72 \\
\hline 4 & 10,9 & 2,8 & 77,06 \\
\hline 5 & 37,5 & 4,7 & 45,27 \\
\hline 6 & 23,7 & 1,6 & 51,29 \\
\hline 7 & 22,5 & 0,7 & 60,81 \\
\hline 8 & 7,5 & 3,86 & 25,92 \\
\hline 9 & 12,6 & 12,6 & 20,74 \\
\hline 10 & 27 & 2,2 & 54,92 \\
\hline 11 & 14 & 0,8 & 80,47 \\
\hline 12 & 25 & 3,4 & 40,5 \\
\hline 13 & 20,2 & 7,6 & 12,83 \\
\hline 14 & 15 & 1,5 & 44,7 \\
\hline 15 & 14,2 & 2,5 & 46,11 \\
\hline
\end{tabular}

Sendo assim, das 15 amostras de água coletadas nas APPs, constatou-se que 5 amostras atendem aos valores máximo permitido pela legislação consultada. Além disso, essas mesmas amostras apresentaram na APP a área de cobertura vegetal nativa superior a 50\% da extensão total. 0 teste de do Coeficiente $p$ de 
Spearman permitiu confirmar que existe associação entre as variáveis $(p=0.8397)$ coliformes termotolerantes e cobertura vegetal nas APPs. Os resultados verificados para total de área de preservação permanente preservada nas localidades estudadas estão expressos na Tabela 4.

Foi possível diagnosticar que a porcentagem de APPs não preservadas estão sendo utilizadas para outras finalidades, tais como pastagem permanente e temporária, vegetação exótica, cultura de milho, canade-açúcar, batata-doce, mandioca, hortifrúti, açudes e benfeitorias. Nesse sentido, é relevante que as APPs, cobertas ou não por vegetação nativa sejam preservadas, com o intuito de conservar os recursos hídricos, a paisagem, a estabilidade geológica e a biodiversidade, o solo e assegurar o bem-estar da população humana (BRASIL, 2012).

Além desses problemas encontrados nas propriedades rurais estudadas, constatou-se que os animais têm acesso direto aos córregos, arroios e sanga, pois são criados soltos em piquetes ou potreiros, intensificando na contaminação dos cursos hídricos por defecando nessas áreas, intensificando o problema quando a chuva carreia esse dejeto para o curso hídrico. O pisoteio dos bovinos também é responsável por provocar erosão na proximidade desses mananciais e nas matas ciliares, sendo necessário a preservação e conservação dos ecossistemas naturais, devido à limitação do estoque dos recursos naturais e nosso compromisso como envolvidos na produção pecuária, de manter e sustentar os recursos, evitando que a degradação se intensifique.

A conscientização para melhor qualidade da água ainda é um desafio para a sociedade, é importante que os produtores rurais busquem parcerias com técnicos da EMATER, Secretaria de Agricultura, Secretaria do Meio Ambiente e biólogos, engenheiros agrônomos e áreas afins, buscando minimizar o aumento de microrganismos patogênicos, garantindo que essas áreas naturais perdurem com boa qualidade à presente e futura geração.

\section{CONCLUSÕES}

O estudo realizado nas propriedades rurais da região do Vale do Taquari/RS, permitiu inferir que $33 \%$ das amostras (5 propriedades rurais) estão de acordo com o VMP estabelecido pela legislação vigente, além disso, essas mesmas localidades apresentaram o percentual da APP coberta por vegetação nativa superior à $50 \%$ da área total. Conclui-se que é necessário elaborar e executar projetos voltados à educação ambiental nessas propriedades rurais fim de capacitar e conscientizar os produtores rurais no que diz respeito ao manejo do gado de leite nas APPs e na qualidade da água.

\section{REFERÊNCIAS}

AMARAL, L. A.. Água de consumo humano como fator de risco à saúde em propriedades rurais. Revista de Saúde Pública, v.37, n.4, p.510-514, 2003.

AOAC. Association of Official Analytical Chemistry. Official methods of analysis. $16 \mathrm{ed}$. Arlington: AOAC International 1995.

ARAÚJO, S. M. V. G.. As áreas de preservação permanente e a questão urbana. Brasília: Câmara dos Deputados, 2002.
BRANCO, S. M.. Água: origem, uso e preservação. 2 ed. São Paulo: Moderna, 2010.

BRASIL. Constituição da República Federativa do Brasil de 1988. Brasília: DOU, 1988

BRASIL. Lei Federal n.12651 de 25 de maio de 2012. Institui o Novo Código Florestal Brasileiro. Brasília: DOU, 2012. 
CERQUEIRA, M. M. O.; PICININ, L. C. A.; FONSECA, L. M.; SOUZA, M. R.; LEITE, M. O.; PENNA, C. F. A. M.. Qualidade da água e seu impacto na qualidade microbiológica do leite. In: MESQUITA, A. J.; DURR, J. W.; COELHO, K. O.. Perspectivas e avanços da qualidade do leite no Brasil. Goiânia: Talento, 2006. p. 273-290.

CONAMA. Conselho Nacional do Meio Ambiente. Resolução n.357 de 17 de Março de 2005. Brasília: CONAMA, 2005.

DIAS, M.. Qualidade da água e desempenho dos bovinos. Campo Grande: Macal Nutrição Animal, 2006.

ECKHARDT, R. R.; SILVEIRA, C. A.; REMPEL, C.. Evolução temporal do uso e cobertura da terra do município de Bom Retiro do Sul-RS-Brasil. Revista Caminhos da Geografia, v.14, n.47, p.150-161, 2013.

FERNANDES, Â. M. F.. Diagnóstico da qualidade da água subterrânea em propriedade rural no município de Planalto, RS. Monografia (Graduação em Geografia) Universidade Regional do Noroeste do Estado do Rio Grande do Sul, ljuí, 2011.

FERREIRA, J. M.. Indicadores de Sustentabilidade em Agroecossistemas. Informe agropecuário, Belo Horizonte, v.33, n.271, p.12-25, 2012.

FUNASA. Fundação Nacional da Saúde. Manual Prático de análise de água. Brasília: FUNASA, 2004.

GONÇALVES, C. S.. Qualidade de águas superficiais na microbacia hidrográfica do arroio Lino Nova Boêmia Agudo - RS. Dissertação (Mestrado em Agronomia) Universidade Federal de Santa Maria, Santa Maria, 2003.

IBGE. Instituto Brasileiro de Geografia e Estatística. Censo Agropecuário 2006. Rio de Janeiro: IBGE, 2006.

LAWARE, A. A. T.; RIFAI, H. S.. Modeling fecal coliform contamination in the Rio Grande. Journal of the American Water Resourses Association, v.42, n.2, p.337-356, 2006.

LENZI, E.; FAVERO, L. O. B.; LUCHESE, E. B.. Introdução à química da água: ciência, vida e sobrevivência. Rio de Janeiro: LTC, 2009.

LIBÂNIO, M.. Fundamentos de qualidade e tratamento de água. 3 ed. Campinas: Átomo, 2010.
MOLINA, P. M.. Diagnóstico da qualidade e disponibilidade de água na microbacia do córrego água da bomba no município de Regente Feijó - SP. Dissertação (Mestrado em Engenharia Civil) - Universidade Estadual Paulista, Ilha Solteira, 2006.

NOGUEIRA, G.. Microbiological quality of drinking water of urban and rural communities, Brazil. Revista de Saúde Pública, São Paulo, v.37, n.2, 2003.

PEREIRA, E. R.; PATERNIANI, J. E.; DEMARCHI, J. J. A. A.. A importância da qualidade da água de dessedentação animal. Revista Brasileira de Engenharia de Biossistemas, Campinas, v.3, n.3, p.227-235, 2009.

RICHTER, C. A.; AZEVEDO NETTO, J. M.. Tratamento de água: tecnologia atualizada. São Paulo: Edgard Blücher, 2013.

ROCHA, C. M. B.. Avaliação da qualidade da água e percepção higiênico-sanitária na área rural de Lavras, Minas Gerais, Brasil, 1999-2000. Caderno de Saúde Pública, Rio de Janeiro, v.22, n.9, p.1967-1978, 2006.

SANTANA, A. S.; SILVA, S. C. F. L.; FARANI, I. O. J.; AMARAL, C. H. R.; MACEDO, V. F.. Qualidade microbiológica de águas minerais. Ciência e Tecnologia Alimentos, v.23, p.190-194, 2003.

SKORUPA, L. A.. Áreas de preservação permanente e desenvolvimento sustentável. Jaguariúna: 2003.

SPERLING, M.V.. Introdução à Qualidade das Águas e Tratamento de Esgotos. 3 ed. Belo Horizonte: UFMG, 2005.

TAVARES, J. E.; BENEDETTI, E.. Água: uso de bebedouros e sua influência na produção de bovinos em pasto. Cadernos de Pós-Graduação da FAZU, Uberaba, v.2, 2012.

TUNDISI, J. G.; TUNDISI, T. M.. Impactos potenciais das alterações do Código Florestal nos recursos hídricos. Biota Neotropica, Campinas, v.10, n.4, p.67-76. 2010.

ZAN, R. A.. Análise microbiológica de amostras de água de poços rasos localizados no município de buritis, região do Vale do Jamari, Rondônia, Amazônia Ocidental. Revista Eletrônica em Gestão, Educação e Tecnologia Ambiental, Cascavel, v.8, n.8, p.1867-1875, 2012.

ZUFFO, C. E.. Caracterização da Qualidade de Águas Superficiais em Rondônia. Anuário do Instituto de Geociências, Rondônia, v.36, n.2, p.25-39, 2013. 